\title{
EM TRÂNSITO: O COTIDIANO DE ALGUMAS AGENTES DE SEGURANÇA PENITENCIÁRIA Do EsTado de SÃo Paulo
}

\author{
Adriana Rezende Faria Taets ${ }^{1}$
}

\begin{abstract}
RESUMO
Aspectos relevantes da trajetória profissional de agentes de segurança penitenciária do Estado de São Paulo são trabalhados neste artigo, de forma a compreender as interrelações entre a instituição prisional e seus funcionários, a partir da ótica destes últimos. Durante a pesquisa realizada foram entrevistadas dez mulheres que trabalham como agentes de segurança penitenciária em diversos presídios do Estado de São Paulo, o que permitiu a identificação de algumas questões que permeiam a profissão em diferentes regiões do Estado, assim como um questionamento acerca do caráter ambíguo desta profissão.
\end{abstract}

Palavras-chave: Agentes de segurança penitenciária. Instituição prisional. Trajetórias profissionais.

\section{IN TRANSIT: THE DAILY LIFE OF SOME FEMALE PRISON SECURITY ofFicers in SÃo Paulo STATE}

\begin{abstract}
This paper discusses some relevant aspects of female prison security officers' professional trajectory in order to understand the interrelations between the prison as an institution and its employees, from the perspective of the latter. Ten female prison security officers, working in different prisons in the State of São Paulo, were interviewed during the research, which made possible the identification of some issues that permeate this profession in different regions of the State, as well as a questioning of the ambiguous character of such occupation.
\end{abstract}

Keywords: Prison security officers. Prison. Professional trajectories.

\footnotetext{
${ }^{1}$ Doutoranda em Antropologia Social pela Universidade de São Paulo, Brasil. dritaets@yahoo.com.br.
} 


\section{INTRODUÇÃO}

0 cotidiano de algumas profissões é bastante conhecido pelo público em geral, seja pela publicidade que se constrói em torno de algumas funções profissionais, seja pela proximidade ou o contato constante que o público mantém com certos profissionais. Isso não acontece com a profissão de agente prisional. Em primeiro lugar porque o exercício de sua função se dá num lugar espacialmente segregado, que são os presídios. Num segundo momento é possível dizer que a falta de conhecimento sobre o cotidiano desta profissão se dá também por uma segregação moral: poucos têm interesse em conhecer o dia a dia de uma pris̃̃o, já que este é interpretado, de uma maneira bastante presente em nossa sociedade, como carregado de riscos e perigos.

A profissão de agente prisional guarda, no entanto, características bastante interessantes em relação à instituição na qual se insere: apesar de atuarem cotidianamente em lugares fechados/segregados da sociedade e conviverem com pessoas que perderam seu direito à liberdade, estes profissionais continuam gozando de sua própria liberdade, ausentando-se dos presídios assim que o turno de trabalho chega ao fim.

Este artigo levanta algumas das questões trabalhadas durante a pesquisa de mestrado realizada com agentes de segurança penitenciária femininas do Estado de São Paulo, durante os anos de 2010 e 2012 que. Esta pesquisa, além do intuito de conhecer a instituição prisional a partir da ótica de algumas de suas funcionárias, teve por objetivo problematizar as trajetórias profissionais de tais mulheres a partir do trânsito cotidiano entre os muros e grades dos presídios onde trabalham (TAETS, 2012). Meu interesse foca-se, assim, não na prisão em si, mas em suas (possíveis) comunicações com o seu entorno, ou ainda, com a sociedade que lhe reserva um espaço (aparentemente) separado.

Para tanto, algumas mulheres foram ouvidas no decorrer da pesquisa2. Estas mulheres trabalham como agentes prisionais, mas são, para além da profissão, sujeitos que fazem parte de uma sociedade livre, fora das grades. No decorrer da pesquisa, 10 agentes prisionais femininas foram entrevistadas e a partir destas entrevistas pude coletar o material que trabalho neste artigo. Este grupo, no entanto, é heterogêneo, sendo formado por mulheres jovens, que estão na carreira há menos de 10 anos, e contou também com mulheres mais velhas, com mais de 20 anos de carreira, outras próximas à aposentadoria, outras já aposentadas.

\footnotetext{
${ }^{2}$ A pesquisa contou com a participação de 10 mulheres que trabalham como agentes de segurança penitenciária no Estado de São Paulo. Com algumas delas mantive um contato prolongado, às vezes por mais de um ano, realizando entrevistas em profundidade e construindo suas histórias de vida. Com outras, as entrevistas foram pontuais, tendo seu foco nas experiências profissionais vividas a partir do trabalho no cárcere.
} 
Além da diversidade de tempo de serviço, o grupo também se mostrou heterogêneo em relação aos postos de trabalho. A maioria das mulheres entrevistadas atua ou atuou em presídios femininos, onde há uma dinâmica específica, como veremos mais à frente. Duas delas atuam ou atuaram em presídios masculinos, onde também há uma lógica própria de trabalho. Por fim, há uma diversidade em relação às cidades onde essas mulheres atuam profissionalmente: três delas trabalham em presídios na cidade de São Paulo ou Grande São Paulo, as demais se encontram alocadas em presídios no interior do estado.

Este artigo trata, portanto, de aspectos específicos desta profissão, revelando alguns dos meandros a partir dos quais tais mulheres constroem suas trajetórias profissionais e modificam, também, a própria instituição prisional.

\section{O PAVILHÃO E A PORTARIA: OS LOCAIS DE TRABALHO DA AGENTE PRISIONAL FEMININA}

A Lei de Execução Penal define que, nos presídios femininos, a tarefa da vigilância deve ser exercida por mulheres. Isso faz que em tais presídios as funcionárias femininas predominem em relação ao efetivo masculino. Os homens, quando presentes, ficam alocados nas portarias e também nos postos da muralha, hoje denominados Agente de Escolta e Vigilância Penitenciária - AEVPs, cargo específico com concurso próprio.

Nos presídios masculinos também há a presença de agentes femininas. Nestes estabelecimentos, geralmente, as mulheres são alocadas na portaria e se responsabilizam pelo trânsito que acontece entre os espaços internos e externos ao presídio. As atividades de uma portaria se voltam para a revista de familiares nos dias de visita, o controle da entrada de materiais e veículos e a inspeção dos funcionários que entram diariamente na unidade prisional. Em algumas unidades, são as mulheres as encarregadas da leitura das cartas que chegam para os detentos, assim como aquelas que os mesmos enviam para algum destinatário. Nas unidades masculinas, as agentes femininas não mantêm nenhum tipo de contato com a população prisional e o mesmo acontece com o efetivo masculino nas prisões femininas.

Num presídio feminino, uma agente prisional pode trabalhar diretamente no raio - local onde ficam as celas das presas -, pode exercer tarefas administrativas ou ser alocada na portaria. Muitas das guardas que se encontram na portaria dos presídios femininos hoje já foram, algum dia, guardas de raio, e isso porque, geralmente, as guardas novatas são diretamente alocadas nos pavilhões.

A trajetória de uma agente prisional que trabalhou em presídios masculinos é bastante diferente daquela que exerceu a profissão em presídios femininos, já que 0 
contato com a população prisional é completamente diversa nos dois cenários, o que faz que a experiência, as percepções e visões sobre a instituição também sejam diversas.

Para o desenvolvimento da pesquisa realizada, pude conversar tanto com agentes prisionais que trabalharam toda a sua trajetória profissional em presídios femininos, atuando em diversos postos de trabalho dentro de tais unidades, assim como travei contato com guardas que passaram todo o tempo de trabalho em presídios masculinos. A partir do cruzamento dos dados coletados pude perceber que algumas questões são típicas de um ou outro tipo de estabelecimento, mas existem outras compartilhadas, presentes em ambos os tipos de atuação.

A partir da fala de diversas interlocutoras da pesquisa foi possível perceber uma hierarquia nos postos de trabalho nos presídios, sendo que os espaços ocupados indicam uma posição particular na carreira: as novatas são, geralmente, alocadas para trabalhar diretamente no raio, em contato intenso com as presas. Depois de um dado período, elas são transferidas para outros postos, que podem ser administrativos, nas enfermarias, escolas etc. A portaria, geralmente, é o local de trabalho de agentes penitenciárias femininas que atuam em presídios masculinos, mas, naquelas instituições voltadas para o público feminino tal posto aparece como um lugar de finalização da carreira: é ali que se encontram muitas das guardas mais velhas. Nas palavras de uma dessas guardas mais antigas, "a portaria é o lugar mais perto da rua".

A partir da fala de algumas agentes, é possível perceber que começa a se desenhar aí uma trajetória profissional marcada pela proximidade ou não das agentes prisionais com as pessoas presas. Quanto mais avança no desenvolvimento da carreira de agente prisional, mais a profissional se afasta do contato direto com as detentas. Essa trajetória, no entanto, não pode ser interpretada como algo "natural" na carreira de uma agente prisional. Ela é, antes, construída institucionalmente. No decorrer da pesquisa, não foram raras as vezes que ouvi de diversos interlocutores ${ }^{3}$, não apenas as guardas entrevistadas, mas também outros atores envolvidos com o sistema prisional, que existe uma norma não escrita de afastar o guarda e a guarda do raio depois de um período de sete anos de trabalho.

A partir desta constatação é possível perceber uma preocupação institucional com o contato direto das guardas com as presas, o que aponta para um risco de identificação e contaminação entre esses dois grupos.

\footnotetext{
${ }^{3}$ Para a realização da pesquisa, também entrevistei outros atores que atuam diretamente no sistema prisional ou próximos a ele, como diretores e funcionários do Sindicato dos Trabalhadores do Sistema Prisional de São Paulo, psicólogos e enfermeiros que atuam dentro de presídios paulistas, advogados e militantes de direitos humanos, assim como pesquisadores que realizam projetos de socialização em alguns presídios paulistas.
} 


\section{AGENTE DE SEGURANÇA PENITENCIÁRIA: UMA PROFISSÃO “IDEAL” PARA A MULHER?}

As razões elencadas pelas agentes prisionais que entrevistei para a procura pela profissão não diferem daquelas trabalhadas tanto pelos estudos acadêmicos, quanto as apontadas por outros atores envolvidos com o sistema prisional ${ }^{4}$. Também elas afirmaram que o emprego público se mostra como uma possibilidade de estabilidade e salários altos frente ao baixo nível educacional exigido.

No ano em que a pesquisa foi realizada, o piso salarial de um agente prisional no estado de São Paulo era de R $\$ 1.200,00$, quase dois salários mínimos. Se formos levar em conta o nível educacional exigido - ensino médio completo, outras possibilidades de emprego voltar-se-iam para o recebimento de apenas um salário mínimo, já que estes seriam considerados profissionais não qualificados, ou seja, não passaram ainda por uma formação técnica ou curso de graduação.

Compreender os motivos pelos quais as agentes prisionais ingressam na profissão é um importante passo para a compreensão da trajetória profissional de tais mulheres, no entanto, é preciso avançar e compreender o que faz com que as agentes prisionais permaneçam na profissão, já que esta é descrita, muitas vezes, como insalubre, opressora ou causadora de diversas doenças (LOURENÇO, 2010; VASCONCELOS, 2000). Afirmar que o salário seria o maior atrativo da profissão é deixar de lado muitas das nuances desta função, não avaliando a importância do jogo de recompensas presentes no funcionamento de uma instituição prisional.

$\mathrm{Na}$ fala de alguns interlocutores - alguns guardas masculinos e também dos diretores do Sindicato da categoria, que foram ouvidos para essa pesquisa - é a rotina do trabalho por turnos o que mantém os agentes prisionais no cargo. A possibilidade de trabalhar 12 horas corridas e depois descansar por 36 é algo que organiza o cotidiano de tais trabalhadores, já que a possibilidade de exercer trabalhos extras - os famosos "bicos" - faz que o agente prisional se adeque a essa rotina e não consiga se desvencilhar dela depois de certo tempo.

Se para os homens o trabalho em turnos é percebido como uma possibilidade da realização de bicos, aumentando, assim, os rendimentos, muitas funcionárias avaliam tal regime como uma possibilidade de cuidar da família e do trabalho doméstico ao mesmo tempo em que se trabalha fora de casa. Certa vez ouvi de uma guarda já com 40

\footnotetext{
${ }^{4} \mathrm{Na}$ maioria dos trabalhos acadêmicos que têm como foco o agente de segurança penitenciária, as razões apontadas para a procura pela profissão voltam-se, principalmente, para a possibilidade de obter um bom salário com baixo nível educacional ver Castro e Silva (2008), Lourenço (2010). 0 mesmo foi dito, por exemplo, por diversos atores envolvidos com o sistema prisional durante a pesquisa realizada por mim, como representantes do sindicato da categoria, advogados e outros funcionários do sistema prisional.
} 
anos de carreira em presídios, prestes a se aposentar, que o trabalho de agente prisional é o ideal para a mulher, exatamente por essas razões. 0 que importa para tal guarda, num momento em que ela se volta para a sua carreira e passa a analisá-la para mim, não é a natureza do trabalho realizado - vigiar pessoas presas seria apenas um detalhe - e sim a possibilidade de estar presente em casa um dia sim e outro não. No dia em que está em casa, a mulher que trabalha com agente prisional poderia, então, exercer as atividades voltadas para o cuidado do lar e dos filhos.

Na visão desta guarda, a profissão de agente prisional resolveria, de certa forma, o paradoxo da mulher ao entrar no mercado de trabalho: como trabalhar fora de casa e realizar as tarefas domésticas ao mesmo tempo? 0 trabalho em regime de turnos seria, uma saída. Ao definir o trabalho "ideal" para a mulher, tal guarda aponta para questões que acionam estereótipos femininos e a relação da mulher com o mercado de trabalho.

Nem todas as guardas entrevistadas, no entanto, avaliam o regime de turnos da mesma maneira e a partir das mesmas questões. No estado de São Paulo, os agentes prisionais, aprovados nos concursos públicos para o preenchimento das vagas, não podem escolher de imediato as regiões onde irão assumir o posto. Com isso, muitos deles são alocados em presídios que ficam muito distantes de suas cidades de origem. Esta realidade faz que muitas mulheres, ao serem aprovadas no concurso, tenham de se mudar para cidades distantes de sua família, o que as separa, muitas vezes, dos filhos. A solução buscada por algumas delas volta-se, na maioria das vezes, para pedidos de transferência de unidades, o que possibilitaria que se mudassem, novamente, para cidades mais próximas de suas famílias.

A dificuldade encontrada, no entanto, está na existência de poucos presídios femininos no estado - não mais que dez - e também nas poucas vagas para mulheres nos presídios masculinos, o que faz com que as transferências para locais mais próximos das cidades de origem demorem ou, mesmo, não aconteçam. A saída encontrada por muitas mulheres é a troca constante de plantões, trabalhando por dias seguidos e por isso, tirando folgas também por dias seguidos, o que permite que voltem para suas cidades de origem mais frequentemente.

A mesma questão, levantada por aquela guarda que dizia que o trabalho de agente prisional é ideal para mulheres, pode ser colocada aqui, a partir de outro ponto de vista: como continuar cuidando dos filhos e da casa com um trabalho que força uma mudança para cidades distantes, sendo que, muitas vezes, tais mulheres se encontram sozinhas para se responsabilizar por estas tarefas? Com quem deixar os filhos nos dias de 12 horas seguidas de trabalho?

A ideia de que o trabalho de guarda é ideal para a mulher aponta para uma visão específica sobre "ser mulher" e sobre as relações familiares. No caso desta guarda mais velha, que apontou a profissão como ideal, percebe-se a presença de uma família em 
que há filhos pequenos e a presença de um marido, como foi o seu caso ao longo de sua própria carreira que foi avaliada de forma positiva. Para outras agentes prisionais entrevistadas, a profissão não é compreendida como ideal, mas, principalmente, como um entrave para o desenvolvimento de muitas de suas atividades domésticas e familiares.

Por outro lado, o regime de turnos é visto como algo positivo ao se levar em conta 0 cotidiano estressante do trabalho prisional. No edital do concurso para agentes prisionais, a função é analisada como sendo de caráter especial, o que justificaria 0 regime de turnos. Apesar do edital não definir no que consiste o "caráter especial", algumas agentes prisionais com quem conversei indicaram a possibilidade de se afastar do presídio por um dia inteiro como um alívio cotidiano frente às pressões sofridas durante 0 período de trabalho. 0 regime de turnos, então, não é avaliado a partir da possibilidade de exercer o bico, nem mesmo como algo que aponta para a realização das tarefas domésticas, mas como uma questão importante para a manutenção da saúde física e emocional do ASP - algo que foi percebido pelo Estado ao definir o "caráter especial" da função.

Percebe-se, portanto, que uma mesma característica do trabalho do agente prisional - 0 regime de turnos - é vivenciado e interpretado de maneiras bastante diversas por aqueles que atuam nessa profissão. A partir das entrevistas realizadas com as guardas prisionais, percebeu-se que a possibilidade de se afastar do presídio por um dia inteiro é algo que permite o desenvolvimento de interpretações variadas sobre suas trajetórias, definindo, por vezes, o caráter da própria profissão.

\section{OCIOSIDADE, MEDO E ANSIEDADE: NO QUE CONSISTE O TRABALHO COTIDIANO DE UMA GUARDA PRISIONAL?}

A portaria de um presídio paulista foi o lugar escolhido por uma de minhas interlocutoras para a realização das entrevistas, o que me permitiu observar por alguns momentos o cotidiano daquele espaço. 0 dia da entrevista, escolhido pela guarda, foi 0 sábado - momento em que a portaria se encontra mais tranquila - já que há apenas a entrada dos religiosos para visitarem as presas.

No sábado, praticamente há muito pouco para fazer numa portaria. Enquanto esperava a guarda com quem iria conversar, me sentei numa salinha improvisada pelas guardas ao lado do portão - com revistas de fofocas, informativos e uma mesinha central com um cinzeiro abarrotado de bitucas de cigarro. Neste tempo, uma das guardas que estavam de plantão trocou meia dúzia de palavras comigo, depois se desculpou, dizendo que tinha que sair porque tinha muito para fazer: "tenho um crochê inteiro para terminar ainda boje!", deu uma gargalhada e me deixou. 
É inexato, no entanto, dizer que as guardas não têm o que fazer na portaria. Durante a semana a rotina é intensa: tudo o que entra e sai do presídio deve ser controlado; números de documentos são anotados, caixas são revistadas, pessoas são inspecionadas. Quando o trânsito entre o dentro e o fora do presídio diminui, no entanto, o que resta a tais funcionárias é estar alerta. Alerta a quê? A qualquer coisa, já que estão ali para, em última instância, vigiar.

0 presídio, segundo a fala de uma guarda entrevistada, que trabalhou toda a sua carreira na portaria de um presídio masculino no interior do estado de São Paulo, é traiçoeiro. Pode parecer calmo, tranquilo, mas num minuto algo sério pode acontecer e uma rebelião estoura - "a cadeia vira", como se diz na linguagem do presídio. A falta de água, a comida ruim ou qualquer detalhe pequeno pode tirar a aparente tranquilidade.

Com isso, as guardas ficam esperando, a todo o momento, que algo excepcional aconteça. A mesma guarda que afirmou que a profissão de agente prisional é ideal para a mulher conta que, assim que começou a trabalhar no presídio, há quarenta anos, perguntou para suas colegas de trabalho o que deveria fazer. A resposta dada foi que ela deveria fazer exatamente o que estava fazendo. Frente à sua perplexidade, a guarda mais experiente explicou: "você deve estar atenta para algo que possa vir a acontecer",

Esse cenário é específico do trabalho realizado nas portarias, tanto nos presídios femininos quanto masculinos. A rotina dentro do pavilhão, por sua vez, é marcada por certa quantidade de tarefas, como a contagem das presas, a abertura das celas para 0 banho de sol, o recolhimento das mesmas às celas, a escolta de alguma detenta para conversar com advogado, psicólogo, médico, dentista, assistente social etc. Mesmo dentro do raio, no entanto, este estado de alerta marca a postura da guarda, já que o presídio é "traiçoeiro", e se espera por algo excepcional a todo o momento.

A postura, sempre alerta e à espera constante, gera ansiedade. Não é à toa que 0 cinzeiro na saleta improvisada pelas guardas na portaria que visitei estava abarrotado. Muitas guardas com quem conversei afirmaram que começaram a fumar no presídio e, muitas delas, mantêm o vício por anos seguidos. Para além do tabagismo, outras doenças são apontadas como consequência do estado de ansiedade constante em que se encontram as guardas: diabetes adquirida; ganho de peso; pressão alta; depressão etc ${ }^{5}$.

0 medo é algo constante: no início da carreira ele é bastante evidente, no entanto, aos poucos, vai-se aprendendo a lidar com ele e chega um momento em que dele se esquece. A mente esquece, acostuma-se, mas, o corpo continua alerta. E é então que os problemas físicos começam.

\footnotetext{
${ }^{5}$ Tais doenças foram citadas pelas guardas entrevistadas como sendo as mais comuns entre as agentes prisionais. As mesmas doenças foram citadas por Vasconcelos (2000) em estudo realizado entre agentes prisionais do Estado do Rio de Janeiro.
} 
Outro problema apontado sobre a ociosidade no trabalho da portaria é a presença de fofoca entre a turma que está de plantão. Se há pouco trabalho, há espaço de sobra para que se converse demais e, com isso, é comum que todas tomem conhecimento sobre a vida umas das outras. Esse também é um fator que gera ansiedade entre elas, já que se sentem vigiadas pelas colegas durante a maior parte do dia. E, assim como o medo, é com o tempo que cada guarda irá aprender a lidar com esta situação.

A ociosidade também está ligada ao caráter não produtivo da atividade prisional. Se o guarda e a guarda estão no presídio para garantir a vigilância, qual é o produto final de seu trabalho? Garantir que os/as presos/as não fujam, que não haja rebelião etc. A atividade do guarda, em geral, não é marcada por um produto final, segundo a fala de uma guarda jovem, que trabalha na portaria de um presídio masculino no interior do estado: "[existe] falta de produtividade, não é um trabalho que você sai e produz, que você se sente bem, a verdade é essa [...], o salário é bom, não é ruim, mas você não se sente muito útil, eu não me sinto". Além da falta de um produto final, a atividade de vigilância é percebida como algo mecânico, em que todo dia é igual ao outro: "A gente sempre comenta na penitenciária: os dias são sempre iguais! Não existe segunda, terça ou quarta, é sempre igual, e não importa a penitenciária, é tudo igual, a rotina é sempre igual".

Percebe-se, portanto, que apesar da dinâmica de uma portaria - a entrada e saída de veículos, a inspeção de pessoas, o controle dos documentos e cartas etc - ainda assim os dias são percebidos como sendo iguais. A repetição das tarefas, o regime de turnos e o estado sempre em alerta fazem com que as guardas se sintam realizando uma atividade não produtiva, o que também é fonte de ansiedade e estresse.

0 trabalho no interior dos presídios - nos raios - é marcado por uma dinâmica diversa, ainda que 0 estado de alerta também seja uma constante. 0 que marca este posto é a proximidade com a população encarcerada, o que acaba por colocar desafios diversos tanto para as guardas prisionais quanto para a própria instituição prisional.

\section{A SEPARAÇÃO ENTRE A REALIDADE PRISIONAL E AQUILO QUE ACONTECE FORA DO CÁRCERE}

As relações existentes entre a sociedade externa ao cárcere e aquilo que ocorre ali dentro é uma tônica na fala das agentes prisionais. A separação entre essas duas realidades, no entanto, é percebida como um pressuposto para uma vida saudável no exercício da profissão de agente prisional. A estrutura física de um presídio é marcada pela separação. Goffman (2005) chama a atenção para os muros, grades ou abismos que separam fisicamente a instituição total do seu entorno. Com isso, a baixa 
comunicabilidade entre o interior e o exterior de tais instituições se torna uma de suas características principais.

Os guardas e as guardas, no entanto, transitam entre tais barreiras físicas, realizando um trânsito cotidiano entre o dentro e o fora dos presídios. Se há razões para que o presídio seja separado fisicamente da sociedade a seu redor, isto faz que o trajeto cotidiano realizado pelos agentes prisionais seja carregado de significados.

A Penitenciária Feminina da Capital, quando inaugurada em 1973, estava sob o comando de freiras. 0 conselho dado por elas para as guardas laicas que chegavam para trabalhar no presídio voltava-se para uma boa separação entre aquilo que era vivido fora do presídio e o que acontecia ali dentro: era preciso esquecer o crime cometido pelas presas, esquecer tudo o que foi ouvido nos jornais sobre tal ou tal detenta. Isso porque, segundo as freiras, a sociedade já havia julgado e condenado aquelas mulheres, logo, as guardas deveriam deixar para o lado de fora do presídio esse tipo de julgamento e, dentro da unidade, tratá-las apenas como mulheres.

As freiras acreditavam que era necessário não trazer para dentro do presídio o julgamento que havia sido feito fora dele, como condição para um bom relacionamento entre as guardas e as presas. Se as freiras se esforçavam para reafirmar a separação entre o dentro e o fora dos presídios é porque, apesar dos muros, tal separação não é evidente. Encontrei nas falas das mulheres com quem conversei um esforço brutal para realizar tal separação, o que na prática se revela num trânsito contínuo entre ideias, questões, sentimentos e julgamentos, entre o que acontece dentro e fora do presídio.

Tal esforço é bastante presente nas falas das mulheres que afirmam, frequentemente, que nunca confundiram a vida vivida dentro do presídio e a vivida fora dele e, por isso mesmo, nunca tiveram grandes problemas. Estes, no entanto, vão aos poucos aparecendo nas falas, a partir do relato de doenças, de desavenças entre as guardas e as guardas e as presas, de decepções com o trabalho etc. 0 trânsito aparece também na experiência adquirida dentro do cárcere e que faz que muitas vezes a guarda lide melhor com o que acontece fora dele.

"Graças a Deus, eu nunca misturei as coisas, nunca confundi as coisas, sempre soube separar muito bem a vida dentro do presídio e o que acontece lá fora", foi uma das primeiras falas de uma das guardas mais velhas com quem conversei, aquela que já estava preparando para se aposentar depois de 40 anos de profissão. Durante a conversa, no entanto, ela aponta que aprendeu muito com as

\footnotetext{
${ }^{6}$ Andrade (2011), a a analisar os documentos de criação dos presídios femininos no Brasil, aponta para a presença de instituições religiosas no comando das unidades prisionais como algo que define o caráter de restauração da mulher criminosa para uma vida piedosa.
} 
presas. Esta aprendizagem voltava-se, principalmente, para as formas como ela deveria lidar com as questões que enfrentava na rua:

Foram as presas que me disseram que não é bom se oferecer para segurar a sacola de alguém que está em pé no ônibus. Se você quiser ajudar, é melhor levantar e oferecer o seu assento para essa pessoa. Vai que na sacola que você está segurando tem droga, a pessoa sai pela porta de trás, a polícia entra pela porta da frente e te pega com uma sacola que nem era sua. Isso eu aprendi com as presas.

Foram as presas também que aconselharam tal guarda sobre a melhor maneira de manter os filhos longe das drogas: "Não é evitando completamente a pessoa que está envolvida com o tráfico, tem que saber respeitar, mas tem que conversar muito também". A convivência com as presas fez que essa guarda aprendesse a lidar melhor com as questões que ela vivenciava na rua, longe dos muros da prisão. A vida vivida na prisão extrapolava seus muros e permitia que ela fosse uma pessoa mais segura do lado de fora das grades.

Outras guardas, no entanto, apontam claramente que não conseguem fazer esta separação entre o que acontece dentro do cárcere e as relações que se dão externas a ele. Esta dificuldade é apontada como problemática, trazendo algumas questões delicadas para a vida cotidiana.

A entrevistada mais jovem com quem conversei, que trabalha na portaria de um presídio masculino no interior do estado, afirma que não consegue se desligar do trabalho mesmo nos dias de folga. Segundo ela, é comum que seu filho reclame que ela está sempre gritando com ele, que está sempre estressada. Ela confessa, então, que não consegue se desligar, que chega em casa e fica pensando nas coisas que aconteceram no trabalho, nas pequenas discussões com os familiares dos presos no momento da revista, nas intrigas entre as guardas da portaria etc.

Apesar das orientações das freiras, que apontavam para o perigo de trazer para dentro do presídio julgamentos que haviam sido realizados fora dele, o problema maior enfrentado pelas guardas parece ser exatamente o contrário, ou seja, levar as questões próprias do presídio para o cotidiano vivenciado no seu exterior. 0 que se percebe é que as doenças que as guardas afirmam ter adquirido a partir da profissão são provenientes daquilo que elas levam de dentro do presídio para as suas vidas fora dele. Era comum ouvir guardas falando sobre colegas de trabalho que não souberam separar os dois momentos e se tornaram violentas em casa, maltratando filhos e maridos.

0 contrário, no entanto, também foi apontado pelas interlocutoras: algumas agentes prisionais são avaliadas como violentas dentro do presídio, abusando do poder de sua função, em decorrência da vida que levam fora do cárcere. Condições ruins fora 
do presídio podem fazer que algumas guardas levem para dentro das unidades suas frustrações e, com isso, abusem do poder frente às presas. Essa outra situação, no entanto, é muito menos presente na fala das guardas, não se colocando como um problema na trajetória delas. A dificuldade em deixar no presídio as questões do presídio, ao contrário, é algo que interfere em outras relações que não apenas aquelas estabelecidas dentro do cárcere.

Muitos dos problemas de "separação" entre o dentro e o fora do presídio se dão, também, devido ao fato de ser bastante difícil compartilhar aquilo que acontece dentro do presídio com pessoas que não conhecem a realidade prisional. A prisão só pode ser conhecida na prática e por quem está lá dentro. Com isso, as guardas se ressentem de uma solidão em relação à sua vida profissional, já que ninguém parece muito interessado em saber o que acontece do lado de dentro dos muros.

Este silêncio quanto ao cotidiano profissional gera bastante ansiedade nos momentos em que as guardas se encontram fora dos muros do presídio. Situações contrárias, no entanto, também são apontadas nas falas: é comum que numa mesma família exista mais de um integrante trabalhando no sistema prisional, o que cria uma situação singular: quebra-se o silêncio sobre a realidade prisional e o cenário familiar é jogado para o outro extremo, em que a cadeia é trazida para casa e o único assunto presente é o sistema prisional. Entre as interlocutoras da pesquisa, pelo menos duas afirmaram que possuíam outros membros da família trabalhando também como agentes prisionais, e, nesses casos, o relato de tais guardas aponta para o fato de que os filhos ou irmãos que não trabalham no sistema prisional reclamam dos modos de falar e dos assuntos daqueles que trabalham em presídios. A cadeia torna-se, assim, o assunto favorito daqueles que trabalham nela e encontram, de alguma maneira, um interlocutor com quem compartilhar a experiência cotidiana.

Em situações como essa, a separação entre o cenário prisional e a vida pessoal e familiar parece não existir, já que os guardas e as guardas trazem para sua casa e suas relações toda a experiência vivenciada dentro do cárcere. Apesar dos muros da prisão da sua separação física em relação ao resto da sociedade na qual se insere - ela está em constante comunicação com a sociedade, em uma circulação constante de ideias, modos de vida, histórias etc.

Ainda pensando no trânsito entre o dentro e o fora dos presídios realizados pelas agentes prisionais cotidianamente, é possível perceber o papel que as guardas prisionais exercem frente à população encarcerada. São elas as pessoas que estão em contato direto com as mulheres presas - no caso das guardas que atuam diretamente nos raios - e representam, portanto, o contato que tais mulheres possuem com o mundo exterior ao cárcere. São as guardas, nas palavras de uma das entrevistadas, que trazem para a prisão "o cheiro da rua", são elas que lhes contam as novidades, que portam algum tipo de 
bijuteria que agora entrou na moda, que trazem um novo corte de cabelo. Diversas detentas recebem visitas familiares, o que poderia também ser considerado um contato que possuem com o mundo externo ao cárcere, no entanto, são as guardas que estabelecem esse contato cotidiano, possibilitando às presas um conhecimento mínimo sobre as coisas que acontecem fora do presídio.

Apesar das grades ou fossos, como apontava Goffman (2005), que buscam diminuir o trânsito e a comunicação entre o dentro e o fora dos presídios, a trajetória de uma agente prisional é marcada, exatamente, por esse constante cruzar de fronteiras, diluindo-as cotidianamente.

\section{CONSIDERAÇÕES FINAIS}

Um olhar mais demorado sobre a profissão de agente de segurança penitenciária a partir da experiência feminina ilumina não apenas questões relacionadas à profissão em si, mas também identifica pontos ainda não trabalhados sobre o cárcere enquanto instituição. Os estudos acadêmicos disponíveis sobre a prisão se voltam, principalmente, para a experiência da pessoa presa, por um lado, ou para questões políticas e institucionais, de outro. Poucas são as pesquisas que tomam 0 agente de segurança penitenciária como objeto de observação. Com isso, pouco se conhece sobre os meandros desta instituição que mantém pessoas cativas, mas também condiciona seus funcionários a agirem de determinada maneira ${ }^{7}$.

A pesquisa realizada com agentes prisionais femininas aponta que, apesar de terem sua vida trespassada pelo cárcere - a partir da convivência cotidiana com a realidade prisional - essas mulheres transitam entre os muros que dividem a prisão e a sociedade, atuando como canais de comunicação que fluem a partir de objetos, histórias, condutas, sentimentos etc. Se, por um lado, elas levam a rua para dentro do cárcere, conforme ouvi algumas vezes nas falas das entrevistadas, tais mulheres também trazem para a sociedade externa ao presídio muito daquilo que acontece dentro do cárcere: visões de mundo, modelos de relacionamento, linguagem etc.

Refletir sobre os trânsitos que as agentes prisionais realizam entre o cárcere e a sociedade mais ampla na qual se inserem possibilita não apenas questionar 0 suposto isolamento dos presídios em nossa sociedade, mas também permite compreender a maneira como esta instituição se insere na dinâmica social e a forma como leva a cabo seu objetivo de segregar pessoas que foram consideradas criminosas pelo sistema judiciário (FOUCAULT, 1987). Analisar as trajetórias profissionais de agentes prisionais

\footnotetext{
${ }^{7}$ Em minha pesquisa de mestrado, realizei um levantamento bibliográfico sobre a produção acadêmica que tem como centro da pesquisa o agente de segurança penitenciário e o pequeno espaço que ela ocupa dentro da literatura que trabalha o cárcere no geral. Ver Taets (2012).
} 
garante uma compreensão de como a instituição é vivenciada por aqueles que permitem seu funcionamento, modificando-a, por vezes, ou reforçando seu aparato legal.

Um olhar sobre as trajetórias profissionais, portanto, possibilita compreender meandros da realidade prisional a partir das relações que se dão dentro do cárcere, o que ainda é pouco explorado pela academia. 0 trânsito cotidiano realizado por agentes prisionais femininas entre 0 dentro e o fora do cárcere nos oferece, então, uma nova possibilidade de perceber e compreender uma instituição que tem nos chamado a atenção pelo seu poder de segregar pessoas e pelas consequências que tal segregação tem gerado para nossa sociedade.

\section{REFERÊNCIAS}

ANDRADE, Bruna Soares Angotti Batista de. Entre as leis da ciência, do Estado e de Deus: o surgimento dos presídios femininos no Brasil. 2011. Dissertação (Mestrado em Antropologia) - Universidade de São Paulo, São Paulo, 2011.

CASTRO E SILVA, Anderson Moraes. Nos braços da lei: o uso da violência negociada no interior das prisões. Rio de Janeiro: e+a, 2008.

FOUCAULT, Michel. Vigiar e punir. Petrópolis: Vozes, 1987.

GOFFMAN, Erving. Manicômios, conventos e prisões. São Paulo: Perspectiva, 2005.

LOURENÇO, Arlindo da Silva. O espaço de vida do agente de segurança penitenciária no cárcere: entre gaiolas, ratoeiras e aquários. 2010. Tese (Doutorado em Psicologia) Universidade de São Paulo, São Paulo, 2010.

TAETS, Adriana Rezende Faria. Abrindo e fechando celas: narrativas, experiências e identidades de agentes de segurança penitenciária femininas. 2012. Dissertação (Mestrado em Antropologia Social) - Universidade de São Paulo, São Paulo, 2012.

VASCONCELOS, Ana Sílvia Furtado. A saúde sob custódia: um estudo sobre agentes de segurança penitenciária no Rio de Janeiro. 2000. Dissertação (Mestrado em Saúde Pública) - Fundação Oswaldo Cruz, Rio de Janeiro, 2000. 